\title{
CÁC NHÂN TỐ ẢNH HƯởNG ĐẾN VIÊCC VẬN DỤNG KẾ TOÁN QUẢN TRI TRONG CÁC DOANH NGHIỆP NHÖ VÀ VỪA TẠI TỈNH BİNH DƯƠNG
}

\author{
HUỲNH TÂN DŨNG ${ }^{1}$, HUỲNH THI THANH THẢO ${ }^{2}$ \\ ${ }^{1}$ Khoa Kế toán - Kiểm toán, Đại Học Công Nghiệp Thành Phố Hồ Chí Minh, \\ ${ }^{2}$ Học Viên Cao Học Kế Toán Khóa 7A, Đại Học Công Nghiệp Thành Phố Hồ Chỉ Minh, \\ huynhtandung_kt@iuh.edu.vn
}

Tóm tắt. Kế toán quản trị đóng vai trò quan trọng trong việc ra quyết định và điều hành doanh nghiệp. Điều này đã được chứng minh qua nhiều nghiên cứu và mức độ ứng dụng trong thực tiễn. Kế toán quản trị được áp dụng rộng rãi tại nhiều quốc gia trên thế giới, không những nó được áp dụng trong các doanh nghiệp lớn mà còn được áp dụng rộng rãi trong các doanh nghiệp nhỏ và vừa. Tuy nhiên ở Việt Nam việc vận dụng kế toán quản trị trong các doanh nghiệp nhỏ và vừa còn rất khiêm tốn. Điều này cũng đã được nhiều tác giả nghiên cứu thể hiện qua các bài báo, các hội thảo. Để góp phần vào các công trình nghiên cứu khoa học, nghiên cứu này được thực hiện nhằm xác định nhân tố và mức độ ảnh hưởng của chúng đến việc vận dụng kế toán quản trị trong các doanh nghiệp nhỏ và vừa trên địa bàn tỉnh Bình Dương. Phương pháp nghiên cứu định tính kết hợp định lượng được sử dùng trong nghiên cứu để tổng hợp, phân tích và kiểm định số liệu thu thập từ cuộc khảo sát 130 doanh nghiệp được chọn theo phương pháp chọn mẫu ngẫu nhiên. Kết quả nghiên cứu cho thấy 7 nhân tố có sự ảnh hưởng việc vận dụng kế toán quản trị trong các doanh nghiệp và mức độ tác động của các nhân tố này lần lược là: Nhà nước và tổ chức nghề nghiệp kế toán $(0,259)$, văn hóa doanh nghiệp $(0,123)$, chính sách quản lý $(0,190)$, đặc điểm doanh nghiệp $(0,183)$, mức độ cạnh tranh $(0,163)$, trình độ nhân viên $(0,143)$, và đào tạo nhân viên $(0,122)$. Trên cơ sở phân tích dữ liệu thu thập được, tác giả đề xuất một số kiến nghị nhằm giúp các nhà quản lý doanh nghiệp thúc đẩy, vận dụng kế toán quản trị để góp phần tăng năng lực cạnh tranh của doanh nghiệp nhỏ và vừa tại tỉnh Bình Dương.

Từ khóa: Nhân tố, vận dụng kế toán quản trị, doanh nghiệp nhỏ và vừa, tỉnh Bình Dương

\section{FACTORS AFFECTING THE APPLYING OF MANAGEMENT ACCOUNTING IN SMALL AND MEDIUM-SIZED ENTERPRISES IN BINH DUONG PROVINCE}

\begin{abstract}
Management accounting plays an important role in decision making and business running. This has been proven through many previous studies and level of application in practice. Management accounting is widely applied in many countries around the world, it is not only applied in large enterprises but also widely applied in small and medium enterprises. However, in Vietnam, the application of management accounting in small and medium enterprises is still very modest. This has also been demonstrated by much research through articles and seminars. To contribute to scientific research, this paper is carried out to determine the factors and their influence on the application of management accounting in small and medium enterprises in Binh Duong province. Qualitative and quantitative research methods are used in research to synthesize, analyze, and verify data collected from a survey of 130 selected enterprises according to random sampling. The research results show that 7 factors affect the application of management accounting in enterprises, including: The State and professional accountancy organizations $(0,259)$, corporate culture $(0,123)$, management policy $(0,190)$, enterprise characteristics $(0,183)$, level of competition $(0,163)$, staff qualifications $(0,143)$, and staff training $(0,122)$. Based on the results of data analyzing, the paper suggests several recommendations to help managers promote and apply management accounting to contribute to increasing the competitiveness of small and medium enterprises in the Binh Duong province.
\end{abstract}

Keywords: Factor, management accounting application, small and medium enterprises, Binh Duong province.

\section{1 ĐẶT VẤN ĐỀ}

Trong bối cảnh nền kinh tế Việt Nam đang trong quá trình hội nhập ngày càng sâu rộng trên thị trường phẳng toàn cầu như tham gia Hiệp định đổi tác toàn diện và tiến bộ xuyên Thái Bình Dương (CPTPP), 
Cộng đồng kinh tế ASEAN (AEC), thông tin kế toán là yếu tố rất quan trọng để tạo nên sức mạnh cho các doanh nghiệp đang đối mặt với nhiều cơ hội nhưng cũng không ít khó khăn, thách thức trong hoạt động sản xuất kinh doanh. Để tồn tại, cạnh tranh và phát triển so với các đối thủ thì những chính sách, chiến lược kinh doanh nhạy bén được đưa ra bởi các nhà quản lý dựa trên thông tin từ kế toán quản trị là điều cần thiết và thường xuyên.

Ở các quốc gia phát triển trên thế giới, kế toán quản trị được xem là một trong những bộ phận cốt lõi tạo giá trị cho doanh nghiệp phát triển bền vững, là quy trình cải tiến không ngừng trong việc hoạch định, thiết kế, đo lường hệ thống thông tin tài chính và thông tin phi tài chính để hướng dẫn, thúc đẩy hành vi của nhà quản trị tạo nên giá trị văn hóa kinh doanh cần thiết nhằm thực hiện chiến lược, chiến thuật và mục tiêu của doanh nghiệp.

Tỉnh Bình Dương là một trong những tỉnh, thành thuộc vùng kinh kế trọng điểm phía Nam - là cửa ngõ giao thương với trung tâm kinh tế - văn hóa của cả nước. Theo số liệu từ cơ sở dữ liệu quốc gia về đăng ký doanh nghiệp (Bộ Kế hoạch và Đầu tư), tính đến ngày 31/12/2019, cả nước có 758.610 doanh nghiệp đang hoạt động, tăng $6,1 \%$ so với cùng thời điểm năm 2018. Theo khu vực kinh tế: Tại thời điểm 31/12/2019, có 508.770 doanh nghiệp đang hoạt động trong khu vực dịch vụ, chiếm $67,1 \%$ trong toàn bộ khu vực doanh nghiệp của cả nước, tăng $6,9 \%$ so với cùng thời điểm năm 2018 . Khu vực công nghiệp và xây dựng có 239.755 doanh nghiệp, chiếm $31,6 \%$, tăng 5,1\%. Khu vực nông, lâm nghiệp và thủy sản có 10.085 doanh nghiệp, chiếm $1,3 \%$, giảm $6,3 \%$.

Theo địa phương: Có 27/63 địa phương có tốc độ tăng doanh nghiệp đang hoạt động thời điểm $31 / 12 / 2019$ so với thời điểm 31/12/2018 cao hơn bình quân cả nước $(6,1 \%)$, trong đó: Bình Dương tăng 14,6\%; Bắc Ninh tăng 14,5\%; Bình Phước tăng 14,2\%; Ninh Thuận tăng 12,7\%; Quảng Nam tăng 11,9\%; Đà Nẵng tăng $10,8 \%$... Có 36/63 địa phương có tốc độ tăng doanh nghiệp đang hoạt động thời điểm 31/12/2019 so với thời điểm 31/12/2018 thấp hơn bình quân cả nước, trong đó có $8 / 63$ địa phương có số doanh nghiệp đang hoạt động tại thời điểm 31/12/2019 giảm so với cùng thời điểm năm 2018 gồm: Hải Phòng giảm 7,8\%; Bắc Kạn giảm 7,6\%; Nghệ An giảm 7,3\%; Lai Châu giảm 5,2\%; Bến Tre giảm 3,3\%; Kiên Giang giảm 1,3\%; An Giang giảm 0,5\%; Lào Cai giảm $0,2 \%$. Như vậy Bình Dương là tỉnh có tốc độ tăng trưởng doanh nghiệp cao nhất nước với 14,6\%

Tuy nhiên thực trạng áp dụng kế toán quản trị trong các doanh nghiệp nhỏ và vừa ở Việt Nam nói chung, ở tỉnh Bình Dương nói riêng còn thấp. Vì thế, việc xác định các nhân tố ảnh hưởng đến việc vận dụng kế toán quản trị trong các doanh nghiệp đặc biệt là doanh nghiệp nhỏ và vừa tại tỉnh Bình Dương rất cần thiết. Đồng thời, kết quả nghiên cứu góp phần giúp cho các nhà quản lý doanh nghiệp nhỏ và vừa vận dụng kế toán quản trị thực hiện tốt việc lập kế hoạch, tổ chức, kiểm soát và đánh giá hoạt động kinh doanh của doanh nghiệp trong bối cảnh nền kinh tế thay đổi liên tục và cần quản lý tình hình tài chính một cách hiệu quả để phát triển bền vững trong quá trình hội nhập kinh tế quốc tế.

\section{CƠ SỞ LÝ LUẬN VÀ Hệ THỐNG LÝ THUYÊT NỀN}

Trong quá trình điều hành, thúc đẩy và kiểm soát các hoạt động kinh doanh, các nhà quản lý doanh nghiệp đều hướng đến mục tiêu tối đa hóa lợi nhuận dựa trên hệ thống thông tin kế toán hiệu quả, đảm bảo rằng các hoạt động liên quan đều diễn ra đúng và theo kế hoạch. Kế toán quản trị là một bộ phận không thể thiếu, cấu thành nên hệ thống thông tin kế toán. Kế toán quản trị đã được nghiên cứu bởi nhiều nhà nghiên cứu, tiêu biểu như:

Theo từ điển kế toán của Nhà xuất bản Macmillan: "Kế toán quản trị là một bộ phận của kế toán liên quan đến việc báo cáo cho các nhà quản trị trong nội bộ doanh nghiệp".

Theo các giáo sư đại học South Florida: "Kế toán quản trị là một hệ thống kế toán cung cấp những thông tin định lượng cho các nhà quản trị, mà họ cần để hoạch định và kiểm soát".

Luật kế toán Việt Nam được Quốc hội thông qua ngày 20 tháng 11 năm 2015 quy định tại Điều 3: "Kế toán quản trị là việc thu thập, xử lý, phân tích và cung cấp thông tin kinh tế tài chính theo yêu cầu quản trị và quyết định kinh tế tài chính trong nội bộ đơn vị kế toán".

Từ một số định nghĩa trên ta thấy, kế toán quản trị là một hệ thống kế toán thu thập, xử lý và cung cấp thông tin cho các nhà quản trị trong nội bộ doanh nghiệp để đưa ra quyết định điều hành các hoạt động kinh doanh. 
Không chỉ dừng ở đây, các nhà nghiên cứu đã tiếp tục tiếp cận kế toán quản trị theo quan điểm đương đại với góc độ thực hành và đã đưa ra những nhận định ngày càng phổ biển, khẳng định vai trò quan trọng của kế toán quản trị như:

Wilson (1997) đã chỉ ra việc sử dụng thông tin kế toán quản trị để hỗ trợ cho việc ra quyết định chiến lược và tác động của thông tin đến kết quả kinh doanh của tổ chức.

Johnson (1981) định nghĩa kế toán quản trị là một hệ thống đo lường, cung cấp thông tin tài chính - kinh doanh và thúc đầy, hỗ trợ các nhà quản lý tạo nên giá trị doanh nghiệp cần thiết để đạt được các mục tiêu chiến lược của tổ chức.

Johnson và Kaplan (1987) đã nhận định, kế toán quản trị là hệ thống cung cấp thông tin kịp thời và chính xác tạo điều kiện cho việc kiểm soát chi phí, đo lường và cải thiện năng suất sản phẩm như quy trình sản xuất, quyết định về giá, giới thiệu sản phẩm mới, từ bỏ các sản phẩm lỗi thời và phản ứng với các sản phẩm của đối thủ.

Trong tài liệu tổng kết các khái niệm kế toán quản trị trên thế giới năm 1998 được công bố bởi Liên đoàn Kế toán Quốc tế: "Kế toán quản trị được xem như là một quy trình định dạng, kiểm soát, đo lường, tổng hợp, phân tích, trình bày, giải thích và truyền đạt thông tin tài chính, thông tin phi tài chính liên quan đến hoạt động của doanh nghiệp cho những nhà quản trị thực hiện hoạch định, đánh giá, kiểm soát, điều hành hoạt động tổ chức nhằm đảm bảo sử dụng có trách nhiệm, hiệu quả nguồn lực kinh tế của doanh nghiệp." IFAC (1998).

Đến năm 2008, Viện các kế toán viên quản trị Hoa Kỳ (IMA) đã tiến hành định nghĩa mới về kế toán quản trị: "Kế toán quản trị là một nghề có liên quan đến việc hố trợ ra quyết định, xây dựng và triển khai kế hoạch và hệ thống quản lý, cung cấp chuyên môn về báo cáo tài chính, kiểm soát để hỗ trợ quản trị trong việc xây dựng và thực hiện chiến lược của tổ chức".

Theo Atkinson Et Al (2012), kế toán quản trị được xem là quá trình cung cấp cho các nhà quản lý và người lao động trong một tổ chức với các thông tin có liên quan về tài chính và cả phi tài chính; đưa ra quyết định, phân bổ nguồn lực và giám sát, đánh giá và khen thưởng việc thực hiện.

Mặc dù có nhiều nhận định về khái niệm kế toán quản trị nhưng hầu hết đều có những điểm cơ bản giống nhau đó là một bộ phận cấu thành hệ thống kế toán, đồng thời cung cấp thông tin và là công cụ hỗ trợ cho nhà quản lý hoạch định, kiểm soát và ra quyết định trong nội bộ doanh nghiệp.

Tóm lại, kế toán quản trị là một môn khoa học thu thập, xử lý, phân tích và cung cấp thông tin tài chính và phi tài chính đồng thời là công cụ quan trọng trong quá trình ra quyết định của nhà quản lý liên quan đến việc lập kế hoạch, tổ chức thực hiện, kiểm tra và đánh giá tình hình thực hiện các hoạt động của doanh nghiệp nhằm tối ưu hóa các mục tiêu chiến lược đã được đề ra.

\section{TỔNG QUAN CÁC NGHIÊN CÚUU TRƯớC}

Trong thời gian qua, có nhiều công trình ngoài nước nghiên cứu các nhân tố ảnh hưởng của việc vận dụng kế toán quản trị trong các doanh nghiệp nhỏ và vừa như:

Eman AL-Hawari, Mahmoud Nassar (2017) đã thiết kế bảng câu hỏi và phân phối cho 100 nhà quản lý tài chính và kế toán được lựa chọn theo phương pháp mẫu ngẫu nhiên để xác định ảnh hưởng của một số yếu tố như quy mô doanh nghiệp, thời gian hoạt động và mức độ cạnh tranh đến việc sử dụng kế toán quản trị được đo lường bởi hệ thống chi phí và hệ thống ngân sách tại các doanh nghiệp nhỏ và vừa tại Jordan. Kết quả của nghiên cứu cho thấy sự tác động của các yếu tố trên có tác động đến việc sử dụng kế toán quản trị.

Hamid Reza Kordlouie, Arash Hosseinpour (2018) nghiên cứu ảnh hưởng của cơ cấu tổ chức, tiềm năng thương mại và hoạt động công nghệ đến việc vận dụng các phương pháp kế toán quản trị tại 342 doanh nghiệp nhỏ và vừa ở các thị trẩn công nghiệp Guilan được chọn ngẫu nhiên từ dữ liệu thống kê.

Omar Albaddad và Mahmoud Nassar (2018) đã tiến hành phân phối bảng câu hỏi được thiết kế đến mẫu ngẫu nhiên đại diện cho tất cả các doanh nghiệp bao gồm 160 kế toán và người quản lý làm việc tại các doanh nghiệp nhỏ và vừa ở Dubai và sử dụng mô hình hồi quy nhiều lần và thử nghiệm mẫu $\mathrm{T}$ để kiểm tra giả thuyết nghiên cứu. Kết quả nghiên cứu thể hiện các doanh nghiệp nhỏ và vừa ở Dubai áp dụng tất cả các thực hành kế toán quản trị (hệ thống chi phí, hệ thống ngân sách, hệ thống đánh giá hiệu suất) có tác động của các nhân tố (mức độ cạnh tranh, thời gian hoạt động, loại ngành, quyền sở hữu và quy mô doanh nghiệp) về việc áp dụng các phương pháp kế toán quản trị được đo lường theo từng hệ thống chi phí, hệ thống ngân sách, hệ thổng đánh giá hiệu năng. 
Theo một nghiên cứu năm 2019 của Mbali, Portia Msomi, Musawenkosi Ngibe, Celani, John Nyide thì các yếu tố như: quy mô, thời gian hoạt động, cấu trúc, trình độ nhân viên, trình độ và kinh nghiệm của giám đốc, môi trường kinh doanh, chính sách hỗ trợ chính phủ, công nghệ ảnh hưởng đến việc áp dụng kế toán quản trị trong các doanh nghiệp sản xuất nhỏ và vừa ở Durban, KwaZulu-Natal thông qua thu thập dữ liệu bởi bảng câu hỏi được phân phối một cách phi xác suất đến giám đốc, nhà quản lý.

Tại Việt Nam, trong những năm qua lĩnh vực này cũng được nhiều nhà nghiên cứu quan tâm đến.

Trần Ngọc Hùng (2016) đã sử dụng kết hợp hai phương pháp nghiên cứu định tính và định lượng nhằm xác định mức độ tác động của nhân tố quyền sở hữu của nhà nước, sự cạnh tranh của thị trường, văn hoá doanh nghiệp, nhận thức của người quản lý doanh nghiệp, quy mô doanh nghiệp, chi phí cho việc tổ chức kế toán quản trị và chiến lược của doanh nghiệp đến việc vận dụng kế toán quản trị trong các doanh nghiệp nhỏ và vừa tại Việt Nam.

Cũng trong năm 2016, Trương Thị Việt Phương (2016), dựa trên kết quả từ bảng câu hỏi được khảo sát bởi chủ doanh nghiệp, người quản lý và kế toán trưởng hoặc kế toán trưởng và ý kiến các chuyên gia như các cán bộ kế toán và tài chính, người quản lý kinh doanh, chuyên gia kỳ cựu cũng như giảng viên và giảng viên tại các trường đại học có hiểu biết sâu sắc về các vấn đề nghiên cứu để xác định và phân tích ảnh hưởng của các yếu tố như hệ thống quản lý, tầm nhìn chiến lược, chi tiết hóa chiến lược, nguồn lao động, áp dụng chuẩn mực và xu hướng đến sử dụng kế toán quản trị trong các doanh nghiệp nhỏ và vừa tỉnh Thái Nguyên.

Sau đó, nghiên cứu của Vũ Thị Thanh Tâm vào năm 2017 từ số liệu thống kê và phân tích, đã trình bày sự ảnh hưởng của các nhân tố về yêu cầu quản lý của doanh nghiệp, tổ chức bộ máy kế toán, trình độ đội ngũ kế toán, quy trình công nghệ và chính sách, pháp luật đến kế toán quản trị chi phí và tính giá thành tại các doanh nghiệp sản xuất có qui mô nhỏ và vừa trên địa bàn thành phố Hà Nội.

Cũng trong thời gian đó, công trình nghiên cứu của Nguyễn Thanh Hợp (2017), dựa trên phương pháp nghiên cứu định tính và định lượng cho thấy rằng trình độ chuyên môn của nhân viên kế toán, nhận thức và sự am hiểu kế toán quản trị của nhà quản lý doanh nghiệp, chi phí doanh nghiệp cam kết cho tổ chức hệ thống kế toán quản trị trong doanh nghiệp, mức độ cạnh trạnh của thị trường là 4 nhân tố có ảnh hưởng đến việc vận dụng này trong doanh nghiệp nhỏ và vừa tại thành phố Biên Hòa tỉnh Đồng Nai.

Vũ Thị Thu Phương (2018), đã đánh giá thực trạng và nhận diện các nhân tố như mục tiêu, chiến lược của doanh nghiệp và nhu cầu thông tin kế toán quản trị chi phí từ phía nhà quản trị doanh nghiệp; đặc điểm tổ chức sản xuất; tình trạng trang bị máy móc thiết bị và trình độ nhân viên thực hiện công việc kế toán; nhận thức của nhà quản trị về vai trò hệ thống thông tin kế toán quản trị chi phí; hành lang pháp lý và môi trường kinh doanh ảnh hưởng hệ thống thông tin kế toán quản trị chi phí trong việc điều hành các doanh nghiệp nhỏ và vừa.

Gần đây, kết quả nghiên cứu năm 2019 của Trần Lâm Mỹ Ái xác định các nhân tố ảnh hưởng đến việc vận dụng kế toán quản trị tại các doanh nghiệp nhỏ và vừa trên địa bàn tỉnh Bình Thuận bao gồm: quy mô doanh nghiệp, mức độ cạnh tranh của thị trường, trình độ nhân viên kế toán, chiến lược kinh doanh và nhận thức về kế toán quản trị của người quản lý doanh nghiệp.

\section{PHƯƠNG PHÁP NGHIÊN CÚU}

Nghiên cứu định tính và nghiên cứu định lượng là hai giai đoạn được tác giả thực hiện trong quá trình nghiên cứu.

Nghiên cứu định tính thông qua thu thập, tổng hợp và phân tích nguồn dữ liệu thứ cấp bằng các công trình nghiên cứu liên quan đã được công bố kết hợp với phỏng vấn các chuyên gia về kế toán quản trị, giảng viên chuyên ngành kế toán quản trị của một số trường đại học để tiến hành đối chiếu, so sánh nhằm xác định hoàn thiện thang đo lường những nhân tố ảnh hương đến việc vận dụng kế toán quản trị trong các doanh nghiệp nhỏ và vừa tại tỉnh Bình Dương.

Nghiên cứu định lượng được tiến hành bằng cách thu thập dữ liệu sơ cấp thông qua bảng câu hỏi được phân phối bằng hình thức qua internet như email, zalo bởi công cụ phần mềm Google Documents hoặc trực tiếp đến giám đốc, trưởng phòng, nhân viên kế toán tại 130 doanh nghiệp nhỏ và vừa bằng phương pháp chọn mẫu phi xác suất, tập trung vào 3 Thành Phố: Thủ Dầu Một, Dĩ An, Thuận An và 2 Thị Xã: Bến Cát, Tân Uyên của tỉnh Bình Dương. Bảng câu hỏi khảo sát được xây dựng gồm các câu hỏi đóng theo thang đo Likert 5 điểm $(1$ - hoàn toàn không đồng ý và 5 - hoàn toàn đồng ý) và các câu hỏi mở nhằm ghi nhận các ý kiến của đối tượng khảo sát. Dữ liệu sau khi thu thập từ 153 phiếu khảo sát thu về 
trong tổng số 174 phiếu đã phát ra sẽ được làm sạch, lọc thu được 133 phiếu khảo sát hợp lệ. Sau đó, tác giả tiến hành mã hóa những thông tin cần thiết, nhập liệu, phân tích dữ liệu để đánh giá thang đo bằng hệ số tin cậy Cronbach's Alpha, kiểm định mô hình bằng phương pháp phân tích nhân tố EFA và các giả thuyết nghiên cứu bởi phân tích hồi quy đa biến.

\section{Mô HÌNH NGHIÊN CúU}

Căn cứ vào tổng quan lý thuyết và tổng quan các công trình nghiên cứu trước như đã trình bày ở trên, ý kiến chuyên gia và lý thuyết nền như lý thuyết đại diện, lý thuyết xã hội học, lý thuyết tâm lý, tác giả đã xây dựng mô hình nghiên cứu với biến phụ thuộc là Việc vận dụng kế toán quản trị trong các doanh nghiệp nhỏ và vừa tại tỉnh Bình Dương (VD) và các biến độc lập là các nhân tố ảnh hưởng bao gồm: Đặc điểm doanh nghiệp (ĐĐ), chính sách quản lý (CSQL), trình độ nhân viên (TĐNV), văn hóa doanh nghiệp $(\mathrm{VH})$, Mức độ cạnh tranh (MĐCT), đào tạo nhân viên ( $\mathrm{OTNV}$ ), nhà nước và tổ chức nghề nghiệp kế toán (NNTCNN).

Với mô hình hồi quy có dạng:

$\mathrm{VD}=\alpha+\beta_{1}$ ĐĐ $+\beta_{2} \mathrm{CSQL}+\beta_{3} \mathrm{TĐNV}+\beta_{4} \mathrm{VH}+\beta_{5} \mathrm{MĐCT}+\beta_{6}$ ĐTNV $+\beta_{7} \mathrm{NNTCNN}+\varepsilon$

Trong đó:

$\alpha$ : Hằng số, $\beta$ i: Hệ số hồi quy, $\varepsilon$ : Sai số

Các nhân tố tác động đến vận dụng kế toán quản trị trong các doanh nghiệp nhỏ và vừa tại tỉnh Bình Dương được thể hiện qua mô hình 1 dưới đây

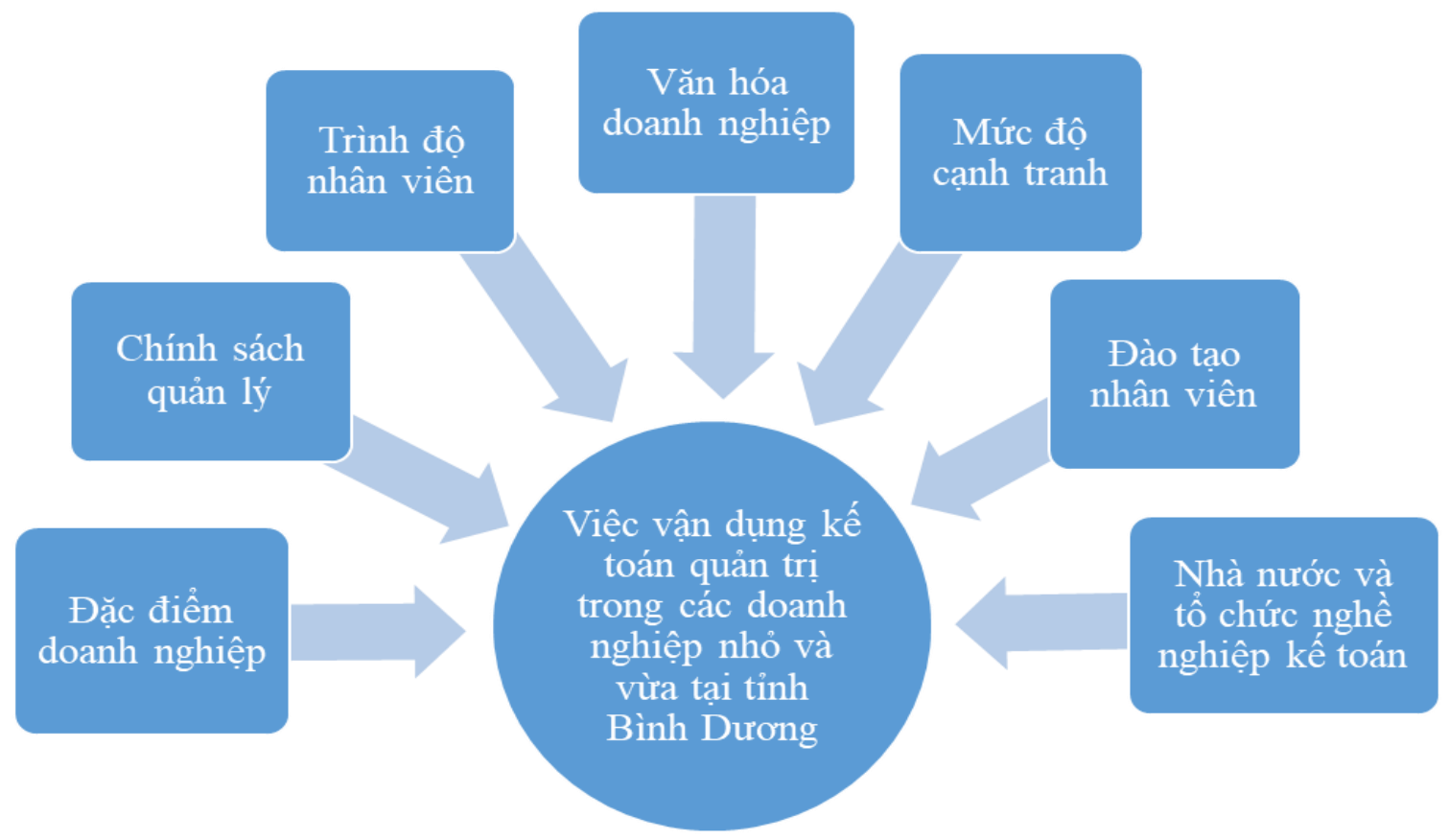

Hình 1. Mô hình nghiên cứu (Nguồn: Tác giả)

\section{KẾT QUẢ NGHIÊN CỨU}

- Kết quả phân tích độ tin cậy của thang đo

Kết quả ở bảng 1 cho thấy, các thang đo của biến độc lập và biến phụ thuộc đều có hệ số tin cậy Cronbach Alpha lớn hơn 0,6 . Hệ số tương quan biến - tổng của các biến quan sát đề̀u lớn hơn 0,3 . Vì vậy, tất cả các biến nghiên cứu với 28 biến quan sát được sử dụng trong phân tích nhân tố khám phá tiếp theo.

Bảng 1. Tổng hợp kết quả kiểm định Cronbach's Alpha

\begin{tabular}{|l|c|c|c|}
\hline \multicolumn{1}{|c|}{ Biến } & $\begin{array}{c}\text { Số biến quan } \\
\text { sát }\end{array}$ & Cronbach's Alpha & $\begin{array}{c}\text { Hệ số tương quan biến - tổng } \\
\text { nhỏ nhất }\end{array}$ \\
\hline Đặc điểm doanh nghiệp & 5 & 0,828 & 0,511 \\
\hline Chính sách quản lý & 4 & 0,697 & 0,406 \\
\hline
\end{tabular}



DOANH NGHIỆP NHỎ VÀ VỬA TẠI TİNH BÌNH DỬNG

\begin{tabular}{|l|c|c|c|}
\hline Trình độ nhân viên & 3 & 0,643 & 0,374 \\
\hline Văn hóa doanh nghiệp & 3 & 0,667 & 0,416 \\
\hline Mức độ cạnh tranh & 4 & 0,723 & 0,439 \\
\hline Đào tạo nhân viên & 3 & 0,621 & 0,382 \\
\hline $\begin{array}{l}\text { Nhà nước và tổ chức nghề nghiệp } \\
\text { kế toán }\end{array}$ & 3 & 0,641 & 0,402 \\
\hline $\begin{array}{l}\text { Việc vận dụng kế toán quản trị } \\
\text { trong các doanh nghiệp nhỏ và } \\
\text { vừa tại tỉnh Bình Dương }\end{array}$ & 3 & 0,574 & 0,309 \\
\hline
\end{tabular}

Nguồn: Tác giả

- Kết quả phân tích nhân tố khám phá

Kết quả phân tích EFA bằng phương pháp trích Pricipal Component với pháp xoay Varimax ở bảng 2 cho thấy dữ liệu nghiên cứu có ý nghĩa và phù hợp.

Kết quả phân tích nhân tố cho các biến độc lập cho thấy cho thấy hệ số $\mathrm{KMO}=0.718$ trong giới hạn cho phép $(0.5 \leq \mathrm{KMO} \leq 1)$ và Bartlett's test of sphericity có giá trị $\mathrm{Sig}=0.000$ nhỏ hơn 0.05 chứng tỏ các biến có tương quan với nhau trong tổng thể. Bên cạnh đó, các nhân tố có kết quả trị số Eigenvalue đạt tiêu chuẩn lớn hơn 1 và có hệ số tải nhân tố lớn hơn tiêu chuẩn cho phép (Factor Loading $>0,5$ ). Tổng phương sai trích là 73,315 có nghĩa là giải thích được $73,315 \%$ sự biến thiên của dữ liệu.

Kết quả phân tích nhân tố cho biến phụ thuộc cho thấy, tất cả 3 biến quan sát đều có hệ số tải nhân tố lớn hơn tiêu chuẩn cho phép (Factor loading $>0,5$ ) và có kết quả trị số Eigenvalue đạt tiêu chuẩn lớn hơn 1. Đồng thời kiểm định Bartlett cho thấy giữa các biến trong tổng thể có mối tương quan với nhau (mức ý nghĩa sig $=0,000<0,05)$ với hệ số $\mathrm{KMO}=0.584(0,5<\mathrm{KMO}<1)$ và tổng phương sai trích đạt $54,089 \%$.

Bảng 2. Kết quả phân tích nhân tố khám phá EFA

\begin{tabular}{|l|l|l|l|l|l|}
\hline \multicolumn{1}{|c|}{ Nhân tố } & $\begin{array}{c}\text { Hệ số } \\
\text { KMO }\end{array}$ & $\begin{array}{c}\text { Sig. (Bartlett's } \\
\text { Test) }\end{array}$ & $\begin{array}{c}\text { Trị số } \\
\text { Eigenvalues }\end{array}$ & $\begin{array}{c}\text { Tổng } \\
\text { phương } \\
\text { sai trích }\end{array}$ & $\begin{array}{c}\text { Hệ số tải nhân } \\
\text { tố }\end{array}$ \\
\hline 1. Biến độc lập & $\mathbf{0 , 7 1 8}$ & $\mathbf{0 , 0 0 0}$ & $\mathbf{1 , 0 0 6}$ & $\mathbf{7 3 , 3 1 5 \%}$ & \\
\hline Đặc điểm doanh nghiệp & & & & & $0,508-0,873$ \\
\hline Chính sách quản lý & & & & & $0,572-0,827$ \\
\hline Trình độ nhân viên & & & & & $0,523-0,836$ \\
\hline Văn hóa doanh nghiệp & & & & & $0,611-0,733$ \\
\hline Mức độ cạnh tranh & & & & & $0,525-0,761$ \\
\hline Đào tạo nhân viên & & & $\mathbf{1 , 6 2 3}$ & $\mathbf{5 4 , 0 8 9 \%}$ & \\
\hline $\begin{array}{l}\text { Nhà nước và tổ chức } \\
\text { nghề nghiệp kế toán }\end{array}$ & & & & & $0,0,524-0,864$ \\
\hline $\mathbf{2 . ~ B i e ̂ ́ n ~ p h u ̣ ~ t h u o ̣ ̂ c ~}$ & $\mathbf{0 , 5 8 4}$ & $\mathbf{0 , 0 0 0}$ & & & \\
\hline $\begin{array}{l}\text { Việc vận dụng kế toán } \\
\text { quăn trị trong các doanh } \\
\text { nghiệp nhỏ và vữa tại tỉnh } \\
\text { Bình Dương }\end{array}$ & & & & & \\
\hline
\end{tabular}

Nguồn: Tác giả

- Kết quả phân tích hồi quy và kiểm định giả thuyết

Kết quả kiểm định tương quan tại bảng 3 cho thấy các biến độc lập có mối quan hệ tương quan thuận với biến phụ thuộc bởi tất cả hệ số tương quan tuyến tính của biến độc lập với biến phụ thuộc đều $>0$ và có ý nghĩa thống kê $\mathrm{Sig}<0,05$ với độ tin cậy $95 \%$. Trong đó, nhân tố tác động mạnh nhất là nhân tố CSQL với $\mathrm{r}=0,618$; nhân tố tác động thấp nhất là nhân tố ĐTVN với $\mathrm{r}=0,203$. Như vậy, tất cả các biến độc lập đều được sử dụng để phân tích hồi quy trong bước tiếp theo. 
Bảng 3. Kết quả phân tích tương quan Pearson

\begin{tabular}{|c|l|r|r|r|r|r|r|r|}
\hline \multicolumn{2}{|c|}{} & ĐĐ & CSQL & TĐNV & VH & MĐCT & ĐTNV & NNTCNN \\
\hline VD & $\begin{array}{l}\text { Tương } \\
\text { quan }\end{array}$ & $0,583^{* *}$ & $0,618^{* *}$ & $0,456^{* *}$ & $0,601^{* *}$ & $0,606^{* *}$ & $0,203^{*}$ & $0,312^{* *}$ \\
\cline { 2 - 9 } & $\begin{array}{l}\text { Sig. (2- } \\
\text { tailed) }\end{array}$ & 0,000 & 0,000 & 0,000 & 0,000 & 0,000 & 0,021 & 0,000 \\
\cline { 2 - 9 } & N & 130 & 130 & 130 & 130 & 130 & 130 & 130 \\
\hline
\end{tabular}

Nguồn: Tác giả

Kết quả phân tích hồi quy tuyến tính về mối quan hệ giữa các nhân tố tác động đến việc vận dụng kế toán quản trị ở bảng 4 chỉ ra 7 nhân tố: Đặc điểm doanh nghiệp (ĐĐ), Chính sách quản lý (CSQL), Trình độ nhân viên (TĐNV), Văn hóa doanh nghiệp (VH), Mức độ cạnh tranh (MĐCT), Đào tạo nhân viên (ĐTNV), Nhà nước và tổ chức nghề nghiệp kế toán (NNTCNN) ảnh hưởng đến biến phụ thuộc có giá trị Sig < 0,05 . Hệ số $\mathrm{R}^{2}$ hiệu chỉnh là 0,600 phản ánh mô hình hồi quy tuyến tính được xây dựng phù hợp với dữ liệu là $60 \%$. Điều này có ý nghĩa là các biến độc lập giải thích $60 \%$ sự biến động của biến phụ thuộc. Hệ số Durbin - Watson là 2,019 trong khoảng $1<\mathrm{D}>3$ chứng tỏ không xảy ra hiện tượng tự tương quan của các phần dư. Kết quả phân tích phương sai chỉ ra giá trị kiểm định $\mathrm{F}=28,628$ với Sig. $=0,000$ nghĩa là mô hình hồi quy tuyến tính phù hợp với tổng thể. Hệ số chấp nhận (Tolerance) thấp và hệ số VIF đều nhỏ hơn 10 chứng tỏ không xảy ra hiện tượng đa cộng tuyến. Điều này cho phép kết luận mô hình hồi quy phù hợp với các dữ liệu với mức ý nghĩa thống kê $5 \%$ có dạng chuẩn hóa là:

VD $=0,259 N N T C N N+0,213 V H+0,190 C S Q L+0,183$ D $+0,163 \mathrm{MĐCT}+0,143$ TĐNV + $0,122 Đ T N V+\varepsilon$

Bảng 4. Kết quả hồi quy các nhân tố ảnh hưởng đến việc vận dụng kế toán quản trị

\begin{tabular}{|c|c|c|c|c|c|c|c|}
\hline \multirow{2}{*}{ Mô hình } & \multicolumn{2}{|c|}{ Hệ số chưa chuẩn hóa } & \multirow{2}{*}{$\begin{array}{c}\begin{array}{c}\text { Hệ số } \\
\text { chuấn hóa }\end{array} \\
\text { Beta }\end{array}$} & \multirow{2}{*}{ Giá trị $t$} & \multirow{2}{*}{ Sig } & \multicolumn{2}{|c|}{ Đa cộng tuyến } \\
\hline & B & $\begin{array}{l}\text { Độ lệch } \\
\text { chuẩn }\end{array}$ & & & & $\begin{array}{c}\text { Hệ số } \\
\text { Tolerance }\end{array}$ & VIF \\
\hline Hằng số & $-0,192$ & 0,394 & & $-0,488$ & 0,626 & & \\
\hline $\begin{array}{l}\text { Đặc điểm doanh } \\
\text { nghiệp }\end{array}$ & 0,132 & 0,053 & 0,183 & 2,463 & 0,015 & 0,564 & 1,773 \\
\hline Chính sách quản lý & 0,153 & 0,067 & 0,190 & 2,290 & 0,024 & 0,452 & 2,212 \\
\hline Trình độ nhân viên & 0,150 & 0,073 & 0,143 & 2,043 & 0,043 & 0,632 & 1,581 \\
\hline $\begin{array}{l}\text { Văn hóa doanh } \\
\text { nghiệp }\end{array}$ & 0,214 & 0,078 & 0,213 & 2,758 & 0,007 & 0,521 & 1,920 \\
\hline Mức độ cạnh tranh & 0,132 & 0,066 & 0,163 & 1,990 & 0,049 & 0,460 & 2,173 \\
\hline Đào tạo nhân viên & 0,088 & 0,044 & 0,122 & 1,995 & 0,048 & 0,825 & 1,213 \\
\hline $\begin{array}{l}\text { Nhà nước và tổ } \\
\text { chức nghề nghiệp } \\
\text { kế toán }\end{array}$ & 0,214 & 0,048 & 0,259 & 4,428 & 0,000 & 0,909 & 1,100 \\
\hline \multicolumn{5}{|l|}{$\mathbf{R}^{2}$} & \multicolumn{3}{|c|}{0,622} \\
\hline \multirow{2}{*}{\multicolumn{5}{|c|}{$\begin{array}{l}\mathbf{R}^{2} \text { hiệu chỉnh } \\
\text { Sai số chuẩn ước lương }\end{array}$}} & \multicolumn{3}{|c|}{0,600} \\
\hline & & & & & \multicolumn{3}{|c|}{0,39891} \\
\hline \multicolumn{5}{|c|}{ Hệ số Durbin-Watson } & \multicolumn{3}{|c|}{2,019} \\
\hline \multicolumn{5}{|c|}{$\mathbf{F}$} & & 28,628 & \\
\hline \multicolumn{5}{|l|}{ Sig } & \multicolumn{3}{|c|}{$\begin{array}{c}\angle 0,020 \\
0,000\end{array}$} \\
\hline
\end{tabular}

\section{KẾT LUẬN VÀ HÀM Ý QUẢN TR!}

\subsection{Kết luận}

Nghiên cứu cho thấy có 7 nhân tố ảnh hưởng đến việc vận dụng kế toán quản trị trong các doanh nghiệp nhỏ và vừa tại tỉnh Bình Dương theo thứ tự giảm dần với hệ số Beta của các nhân tố: Nhà nước và tổ chức nghề nghiệp kế toán $(0,259)$; Văn hóa doanh nghiệp $(0,213)$; Chính sách quản lý $(0,190)$; Đặc điểm doanh nghiệp $(0,183)$; Mức độ cạnh tranh $(0,163)$; Trình độ nhân viên kế toán $(0,143)$ và cuối cùng là Đào tạo nhân viên $(0,217)$. Kết quả nghiên cứu này có sự tương tự với kết quả của các nghiên cứu trước 
đó của Eman AL-Hawari, Mahmoud Nassar (2017), Hamid Reza Kordlouie, Arash Hosseinpour (2018), Omar Albaddad và Mahmoud Nassar (2018), Mbali, Portia Msomi, Musawenkosi Ngibe, Celani, John Nyide (2019), Trần Ngọc Hùng (2016), Trương Thị Việt Phương (2016), Vũ Thị Thanh Tâm (2017), Nguyễn Thanh Hợp (2017), Vũ Thị Thu Phương (2018) và Trần Lâm Mỹ Ái (2019).

\subsection{Hàm ý quản trị}

Từ kết quả trên, tác giả gợi ý một số hàm ý chính sách sau để việc vận dụng kế toán quản trị trong các doanh nghiệp nhỏ và vừa tại tỉnh Bình Dương được phổ biến và hiệu quả hơn:

Đối với nhà nước và tổ chức nghề nghiệp kế toán: Đây là yếu tố quan trọng nhất tác động đến việc có vận dụng kế toán quản trị trong các doanh nghiệp hay không. Vì thế, cần thiết lập môi trường pháp lý đầy đủ về tổ chức hoạt động kế toán quản trị như ban hành những văn bản quy định rõ ràng về vai trò, chức năng, nhiệm vụ và việc tổ chức, triển khai kế toán quản trị trong doanh nghiệp bởi đến thời điểm hiện nay, Nhà nước chưa có hướng dẫn cụ thể mà chỉ mới ban hành Thông tư số 53/2006/TT-BTC ngày 12/06/2006 hướng dẫn áp dụng chung kế toán quản trị trong doanh nghiệp. Bên cạnh đó, Nhà nước và tổ chức nghề nghiệp kế toán cần triển khai các chương trình hỗ trợ trực tiếp, gián tiếp cho các doanh nghiệp tiếp cận với kế toán quản trị đồng thời tăng cường gia tăng vai trò quản lý, đào tạo bồi dưỡng chuyên môn cho đội ngũ kế toán của các tổ chức nghề nghiệp kế toán hay việc tuyên truyền, quản bá, thúc đẩy về tầm quan trọng, nội dung và kỹ thuật kế toán quản trị cũng như các mô hình kế toán quản trị trên các phương tiện đại chúng để doanh nghiệp thấy rõ sự cần thiết phải tổ chức hệ thống kế toán quản trị̣.

Đối với văn hóa doanh nghiệp: Cần xây dựng môi trường làm việc có sự hợp tác, gắn kết chặt chẽ hay sự chia sẻ, hỗ trợ lẫn nhau theo chiều ngang giữa các nhân viên và theo chiều dọc giữa lãnh đạo và các nhân viên không phân biệt phòng ban trong đơn vị góp phần thúc đẩy sự thành công khi vận dụng kế toán quản trị trong doanh nghiệp.

Đối với chính sách quản lý: Nhà quản lý doanh nghiệp cần thay đổi tư duy và cách nhìn về kế toán quản trị khi thực hiện các chức năng quản trị của mình, đồng thời cần nhận thức vai trò và tầm quan trọng của thông tin từ bộ phận kế toán quản trị - đã được tổ chức, xây dựng theo mô hình thích hợp với đặc điểm hoạt động sản xuất kinh doanh của doanh nghiệp - cung cấp để chỉ đạo, thúc đẩy và kiểm soát các hoạt động, mục tiêu chiến lược.

Đối với đặc điểm doanh nghiệp: Cần xây dựng cơ cấu tổ chức với các phòng ban được đầu tư các trang thiết bị, phương tiện kỹ thuật, máy móc có công nghệ tiên tiến tùy theo quy mô hoạt động và danh tiếng trên thị trường cũng như nguồn lực tài chính của đơn vị.

Đối với mức độ cạnh tranh: Khi mức độ cạnh tranh của thị trường ngày càng khốc liệt hơn khi luôn có sự xuất hiện của các đối thủ cạnh tranh mới, các sản phẩm thay thế mới trên thị trường trong thời kỳ nền kinh tế nước ta ngày càng hội nhập sâu vào nền kinh tế khu vực và thế giới thì các doanh nghiệp nhỏ và vừa ở tỉnh Bình Dương nói riêng và Việt Nam nói chung cần vận dụng kế toán quản trị để nắm bắt nhanh chóng, chính xác những thông tin biến động và xu thế phát triển của thị trường. Từ đó, doanh nghiệp sẽ thay đồi, điều chỉnh các chính sách về giá cả, phân phối, marketing nhằm nâng cao thị phần các sản phẩm của doanh nghiệp.

Đối với trình độ nhân viên kế toán: tăng cường đầu tư đội ngũ nhân viên am hiểu về kế toán quản trị đồng thời có nghiệp vụ về kế toán tài chính và sử dụng thành thạo các phần mềm hỗ trợ xỷ lý và kết xuất thông tin từ nguồn dữ liệu một cách nhanh chóng và có hiệu quả hay tuyển dụng nhân sự mới có chuyên môn về kế toán quản trị là rất cần thiết để đáp ứng yêu cầu của công tác kế toán và kế toán quản trị.

Đối với đào tạo nhân viên: Các kế toán viên tương lai và hiện tại nên chú trọng bồi dưỡng, nâng cao nghiệp vụ chuyên môn về kế toán quản trị như tham gia sinh hoạt, học tập bồi dưỡng thường xuyên và liên tục ở các hội nghề nghiệp hay nghe giảng và nói chuyện chuyên đề các chuyên gia nhằm tăng tính thực tế về mô hình kế toán quản trị.

Tóm lại, nghiên cứu đã xác định các nhân tố và đo lường mức độ ảnh hưởng của các nhân tố này đến việc vận dụng kế toán quản trị trong các doanh nghiệp nhỏ và vừa tại tỉnh Bình Dương. Vì thế, nghiên cứu này sẽ là tài liệu tham khảo hữu ích cho các doanh nghiệp nhỏ và vừa xem xét, cân nhắc và có các điều chỉnh cần thiết đối với việc vận dụng kế toán quản trị tại đơn vị của mình. Tuy nhiên, nghiên cứu chỉ dừng lại ở các doanh nghiệp nhỏ và vừa trên địa bàn tỉnh Bình Dương mức độ giải thích của mô hình chỉ là $60 \%$ cho thấy còn $40 \%$ việc vận dụng kế toán quản trị bị chi phối bởi các nhân tố khác. Do đó, các nghiên cứu trong tương lai cần mở rộng quy mô và khám phá các nhân tố mới. 


\section{Giới Hạn Của Nghiên Cứu Và Hướng Nghiên Cứu Tiếp Theo}

Trong nghiên cứu này nhóm tác giả thực hiện phân tích trên mẫu 130 doanh nghiệp nhỏ và vừa tại 3 Thành Phố: Thủ Dầu Một, Dĩ An, Thuận An và 2 Thị Xã: Bến Cát, Tân Uyên của tỉnh Bình Dương. Trong tương lai nhóm tác giả mở rộng nghiên cứu sang tất cả các thị xã và huyện còn lại của Bình Dương.

\section{LÒ̀I CẢM ƠN}

Chúng tôi gởi lời cảm ơn tới tới tất cả các doanh nghiệp nhỏ và vừa trên địa bàn tình Bình Dương đã tạo điều kiện cho chúng tôi thực hiện nghiên cứu này. Chúng tôi cũng gởi lời cảm ơn tới các đồng nghiệp và những người cộng tác. Sau cùng chúng tôi cảm ơn đến tất cả các tác giả mà chúng tôi trích dẫn trong bài báo.

\section{TÀI LIỆU THAM KHẢO}

[1]. R. H. Parker, 1984, 1992 Dictionary of accounting, second edition, Macmillan Press LTD, Page 182.

[2]. Luật kế toán Việt Nam 2015, luật số 88/2015/QH13

[3]. Wilson, RM, 1997. Strategic cost management. Dartmouth: Ashgate.

[4]. Johnson, H. T., \& Kaplan, R. S, 1987. Relevance Lost: The Rise and Fall of Management Accounting. Boston, Massachusetts: Harvard Business School Press.

[5]. IFAC, 1998. International Management Accounting Practice Statement: Management Accounting Concepts. New York.

[6]. Atkinson, A. A. et al. 2012. Management accounting: information for decision-making and strategy execution. 6th ed. Boston: Pearson.

[7]. Nguyễn Ngọc Quang và cộng sự, 2012. Giáo trình kế toán quản trị. Hà Nội: Nhà xuất bản Đại Học Kinh Tế Quốc Dân.

[8]. Eman AL-Hawari, Mahmoud Nassar, 2017. The factors affecting the different management accounting practices in small and medium sized enterprises in Jordan, International Journal of Academic Research in Business and Social Sciences, Vol. 7, No. 12, Page 970 - 978.

[9]. Hamid Reza Kordlouie, Arash Hosseinpour, 2018. Management accounting practies in small and medium sized enterprises regarding the impact of organizational, commercial potential and operational technology, International Journal of Business Quantitative Economics and Applied Management Research, Volume 4, Issue 8, Page $22-31$.

[10]. Omar Albaddad, Mahmoud Nassar, 2018. Factors influencing the implementation of management accounting systems in small and medium sized enterprises in Dubai, International Business Research, Vol. 11, No. 1, Page $245-252$.

[11]. Mbali, Portia Msomi, Musawenkosi Ngibe, Celani, John Nyide, 2019. Factors influencing the adoption of management accounting practices (MAPs) by manufacturig small and medium enterprises (SMEs) in Durban, Kwazulu-Natal, International Journal of Entrepreneurship, Volume 23, Issue 4.

[12]. Trần Ngọc Hùng, 2016. Các nhân tố tác động đến việc vận dụng kế toán quản trị trong các doanh nghiệp nhỏ và vùa tại Việt Nam. Luận án Tiến Sĩ. Đại Học Kinh Tế Thành Phố Hồ Chí Minh. 
[13]. Trương Thị Việt Phương, 2016. The solutions to enhance the use of management accounting in small and medium enterprises in Thai Nguyen Province, Business and Economics Journal, Volume 7, Issue 4, Page $1-4$.

[14]. Vũ Thị Thanh Tâm, 2017. Các nhân tố ảnh hưởng đến kế toán quản trị chi phí và giá thành trong các doanh nghiệp sản xuất qui mô vừa và nhỏ trên địa bàn thành phố Hà Nội, Tạp Chí Công Thuơng.

[15]. Vũ Thị Thu Phương, 2018. Về vai trò của hệ thống thông tin kế toán quản trị trong các doanh nghiệp nhỏ và vừa ở Việt Nam, Tạp Chi Kế Toán Và Kiểm Toán, số tháng 5.

[16]. Nguyễn Thanh Hợp, 2017. Các nhân tố ảnh huởng đến viêc vận dụng kế toán quản trị trong các doanh nghiệp nhỏ và vì̀a tại Thành phố Biên Hòa. Luận văn Thạc Sĩ. Đại Học Công Nghệ Thành Phố Hồ Chí Minh.

[17]. Trần Lâm Mỹ Ái, 2019. Các nhân tố ảnh hương đến viêc vận dụng kế toán quản trị tại các doanh nghiệp nhỏ và vìa trên địa bàn tỉnh Bình Thuận. Luận văn Thạc Sĩ. Đại Học Kinh Tế Thành Phố Hồ Chí Minh.

[18]. Johnson, 1981. Toward A New Understanding of Nineteenth Century Cost Accounting, The Accounting Review, Vol.56, No.3.

Ngày nhận bài: 07/10/2020

Ngày chấp nhận đăng: 03/02/2021 